\title{
Intellectual character of metacognition in thinking strategies
}

\author{
Ayu Niza Machfauzia1, Djohan², Phakkharawat Sittiprapaporn ${ }^{3}$ \\ ${ }^{1}$ Lecturer, Department of Music Education, Yogyakarta State University, Yogyakarta, Indonesia, ${ }^{2}$ Professor, Graduate \\ School of Indonesia Institute of the Arts Yogyakarta, Yogyakarta, Indonesia, ${ }^{3}$ Assistant Professor and Head, Brain \\ Science and Engineering Innovation Research Group, School of Anti-Aging and Regenerative Medicine, Mae Fah \\ Luang University, Bangkok, Thailand, and Department of Anti-Aging Science, School of Anti-Aging and Regenerative \\ Medicine, Mae Fah Luang University, Bangkok, Thailand
}

A B S TR A C T

Background: Metacognition is one aspect of intellectual character about a concept that has been used to refer to a variety of epistemological processes. Metacognition essentially means cognition about cognition; that is, it refers to second-order cognitions: thoughts about thoughts, knowledge about knowledge or reflections about actions. Previous research explained that metacognition is useful in many educational settings and can be transferred from the music classroom to other subject areas. Aims and Objective: This study aimed to reveal aspects of student metacognition as a strategy used in playing music. Materials and Methods: In this observational study, the spontaneous metacognitive behavior of students during guitar lessons in guitar classroom was analyzed. Results: Data from interviews revealed that students were weak in metacognitive behavior, so that students do not use thinking ways of thinking. This is because the lecturer cannot promote metacognition by designing and implementing instructional strategies that encourage music students to engage in reflection, self-assessment, and thinking critically.Based on the results of research that has been obtained, it can be said that in playing music, especially in the guitar class, it is important to know what is known about the music that will be played. Conclusion: Lecturers need to promote metacognitive awareness in students, so that students are able to develop their thinking strategies well in playing music, especially in guitar classes.

\section{Access this article online}

Website:

http://nepjol.info/index.php/AJMS DOI: 10.3126/ajms.v11i1.26519 E-ISSN: 2091-0576 P-ISSN: 2467-9100

Key words: Metacognition; Thinking; Music; Guitar classroom

\section{INTRODUCTION}

Metacognition is one aspect of intellectual character about a concept that has been used to refer to a variety of epistemological processes. Intellectual character is a set of attributes or disposition that distinguish a person as someone who is able to think clearly and effectively. ${ }^{1}$ In contrast to cognition, metacognition is a need to understand how the task was performed. ${ }^{2}$ Tobias and Everson ${ }^{3}$ in his research linked various disciplines in explaining the concept of metacognition. They explained that metacognition is one of the most widely studied constructs in contemporary psychological research in educational, instructional, and developmental psychology. In education, metacognition describes the processes involved when learners plan, monitor, evaluate, and make changes to their own learning behaviors.

According to Louca ${ }^{4}$ the educational benefits of the application of metacognitive strategies such as selfawareness and self-monitoring include the development of independent learners who control their own learning and learn how to learn for life. This reinforces the results of Benton's research about promoting metacognition in music classes. In his research, Benton ${ }^{5}$ explained that metacognition is useful in many educational settings and can be transferred from the music classroom to other subject areas. In addition, Hallam ${ }^{6}$ expressed that metacognition appears to be a key factor for musicians, since the use of metacognitive strategies (e.g., planning, 
monitoring, and evaluation) during practice improves the performance of both novices and experts. Therefore, music educators can promote and implement metacognition strategies continuously in musical instrument practice learning. By doing so, music educators can help students develop thinking skills that will enhance their cognitive involvement.

Benton $^{5}$ stated that through the use of instructional strategies that promote metacognition, music educators can: (1) increase students' cognitive engagement in musicmaking; (2) help students to become lifelong music-makers by developing necessary thinking strategies for musical selfreliance; and teach thinking skills in music classroom that will transfer to other discipline. ${ }^{3}$ It shows that by promoting metacognition, students can perform self-control and improve thinking ability in working out the music.

From several studies that have been conducted, it can be said that the importance of promoting and developing metacognitive skills in music learning. However, based on observations made on music students who play music in guitar classes, in particular, there are still many students who only use visual perception in playing musical work. They do not use knowledge to examine the musical elements contained in scores. This causes the quality of the music played to be less good. This empirical experience was strengthened by Hallam ${ }^{6}$ who stated musicians usually tend to have an overview of the piece they intend to play or sing and the way to acquire this is to have a good internal aural representation of the music from examination of the score only. In contrast to the research that has been conducted, this study reveals student metacognition behavior which is used as a strategy of thinking in playing music in the guitar class.

\section{MATERIALS AND METHODS}

\section{Participants}

Twenty-two students who took part in guitar practice learning were involved as participants in this study. In the repertoire class section, one by one student is asked to play a piece of music that has been learned. When students play musical work, the student is observed in his metacognition behavior. After finishing playing music, other students comment on the work that has been played.

Metacognition awareness: Strategy thinking students in playing music

Strategic thinking, an integral part of metacognitive awareness, allows learners to access prior knowledge, monitor comprehension, correct misconceptions, synthesize information, draw inferences, and ask questions. As a result, they begin to understand and own their cognitive processes. Haynie and Shepherd ${ }^{7}$ explained that the greater an individual's metacognitive awareness, the more adaptive the individual is given a changing decision context. In the context of cognitive adaptability, Haynie and Shepherd ${ }^{7}$ describe each of the dimensions represented in the process model (Figure 1).

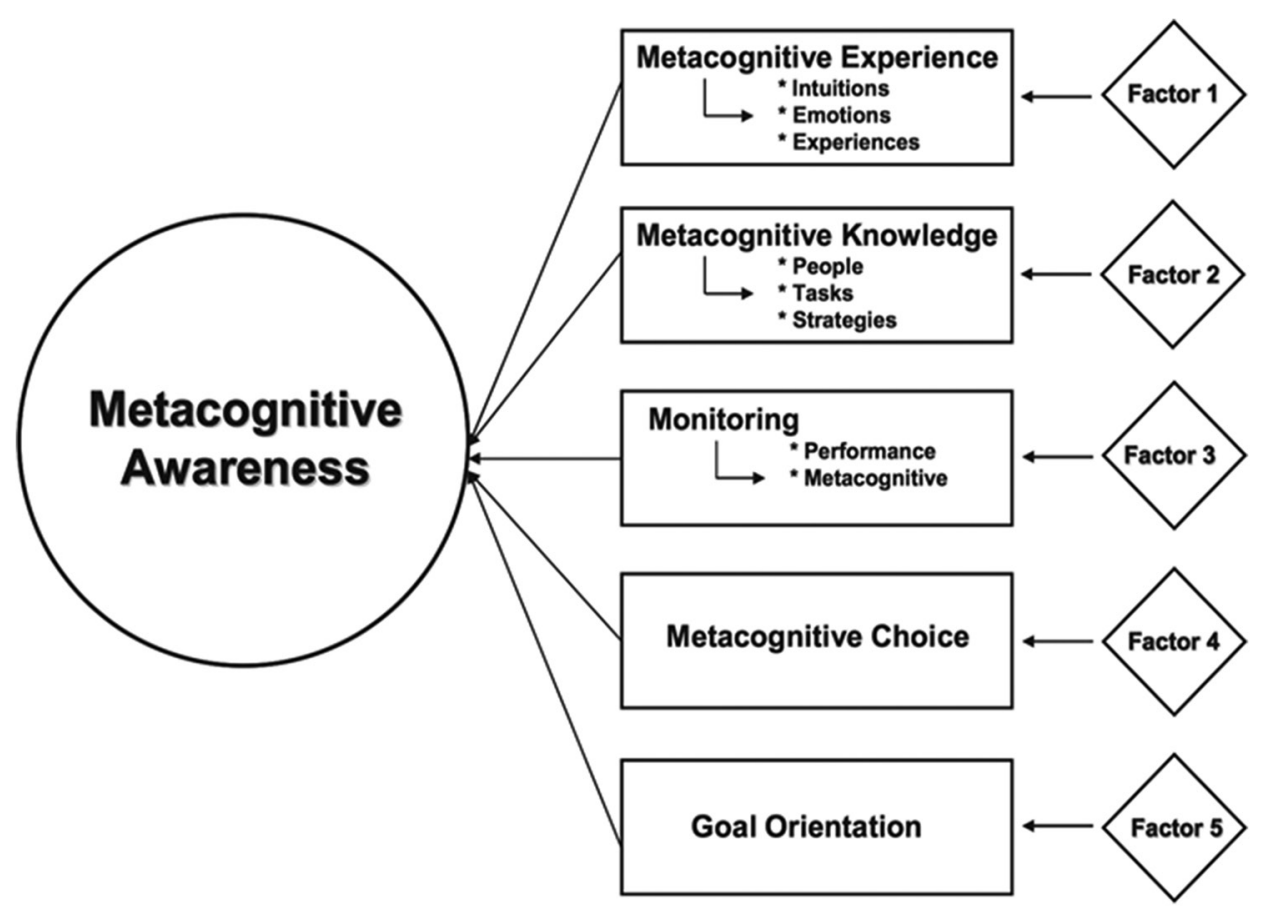

Figure 1: Hierarchical dimensions of metacognitive awareness 5-Factor solutions 
In Figure 1, it appears that there are five solution factors for gaining metacognition awareness, namely metacognitive experience, metacognitive knowledge, monitoring, metacognitive, and goal orientation. Everson \& Tobias in Akman and lag z8 suggested that metacognition makes students more strategic in learning. Furthermore, Akman and lag z8 explain that metacognitive awareness provides students with the opportunity to plan, to monitor and to evaluate their own learning, so that students who take their own responsibilities in all parts of the learning process apply their knowledge to encountered problems more easily and become more successful.

In playing music, students are not only required to be skilled, but also able to understand, and analyze the works of music played. To be able to analyze a musical work, a thinking strategy is needed to be able to map cognitive abilities related to the knowledge of musical elements contained in the music score. In order for this to be achieved, lecturer can promote metacognition by designing and implementing instructional strategies that encourage music students to engage in reflection, self-assessment, and thinking critically well.

\section{Data collection}

Data in the form of metacognitive behavior, namely the ability to think of students in playing music in the guitar class, is collected through continuous observation when the learning process in the guitar class takes place. Furthermore, the data is generated through interviews both face to face and by FGD. Data in the form of meta-comprehensive in the knowledge and ability to read music scores was collected by giving questionnaires to 22 students.

\section{Procedure}

Twenty-two students who took part in guitar practice learning were observed when the learning process took place. Not only students, but lecturers were observed while teaching, and interviewed as well. From the observations made, it seems that there are still many students who do not use the strategy of their thinking ability in playing music. Meanwhile, the results of the interview indicate that students still find it difficult to read music. To strengthen the data that has been collected, documentation techniques are also used in the form of photos. After the lecture was completed, a number of 7 students were interviewed to find out their metacognitive behavior in the form of their thinking strategies in playing musical works. In order for the results of the interviews to be trusted, the FGD was conducted with 22 students and one lecturer. In the FGD class, students were asked to fill out a questionnaire to determine the ability to read the overall music score.

\section{Data analysis}

In this study, qualitative data were analyzed using the interactive model which consisted of data reduction, data presentation, and data verification. Meanwhile, quantitative data were analyzed using the percentage formula. Qualitative data is in the form of observational data on students' metacognitive behavior in playing music in guitar classes. Quantitative data in the form of data to measure one stage of knowledge metacognition and comprehensive strategies related to music knowledge contained in the music score used a questionnaire from the meta-comprehensive strategy Index (MSI). ${ }^{3}$

\section{RESULTS}

The results of observations carried out continuously during guitar learning took place, showing that almost all students only used visual perceptions in playing the music they learned. They also do not use listening perceptions. In fact, playing music requires the perception of listening, both listening to music that is played by themself, and the music played by other musicians. This was revealed from the results of interviews with students (Hna) as follows.

"If I play songs just concentrate on the score, because I can't read the notation properly".

The expression shows the weakness of thinking strategies in overcoming the problem of difficulty reading the music score. This affects the lack of knowledge related to the elements of music contained in it. Unlike Hna, Itn revealed that it could not be separated from the music score, as shown in the interview results as follows.

\section{"I can't play music, if I don't see the score. I am afraid of playing the notes".}

This condition occurs in almost all students in the guitar class. They still find it difficult to read the music score. When they play music, it is not analyzed first. In addition, it is not studied in detail the elements of music contained in it. Most of them do not use their thinking strategies in developing their knowledge and skills in playing music. There are times when they cannot distinguish the types of rhythms contained in the music score. However, there are five students who have the ability to think well than other students in playing music. One of them reveals that it is necessary to examine in detail in advance the aspects of music contained in the music score. This was revealed in the results of the interview with the Ats as follows.

"I always carry a pencil if I want to practice music. I will mark the part that I don't understand". 
The Ats expression shows the ability to think critically in playing music. Ats first analyzes the music that will be played. In addition, Ats also marks with a pencil in parts that are not understood in the music score. In this case, Ats is aware of the things that need to be done in playing music, especially in guitar learning. Seems like, students use different strategies to learn and process the information presented in the classroom.

Other students who have the ability to think strategically like the Ats, namely Dry. Dry showed metacognitive awareness in playing music, both before playing music, while playing music, and after playing music. This expression is evidenced in the results of the interview as follows.

"Before playing a musical piece assigned by a lecturer, I first examined various aspects of music contained in music scores. I analyzed it, then I applied it to playing the music"

The results of the interview show Dry has a good thinking strategy, and also has good metacognition awareness. Dry already knows and does how this new knowledge is acquired and organized.The results of the interview with Dry are reinforced by the results of research conducted by Leon et $\mathrm{al}^{9}$ which explains that the difference between someone with and without experience is not only the amount of knowledge that they possess, but also, and perhaps even more important, how this new knowledge is acquired and organized. In fact, the fact that students think and critically analyze what they are learning has been associated with academic performance.

Overall, most students in playing music still use visual perception, and directly play music without being studied and analyzed first the elements of music contained in it, such as tempo marks, time signature, key signature, dynamics, expressions, tone value, rhythm, and chord. That is, in playing the assigned musical work, almost all students only read the melody, so many musical elements were not noticed, and were not played well. This condition shows the weak thinking ability of students in playing music. They do not use their strategies and thinking skills to the fullest. The results of this study were also reinforced by quantitative data given to all participants involved. The results of the study in the form of quantitative data revealed the students' comprehensive research that revealed meta-skills in terms of reading music scores.

The results of research that revealed students' metacomprehension strategies in reading music scores shows that as many as 5 students (23\%) have a good metacomprehension strategy. This is shown in the points before reading, while reading, and after reading the music score more on the answer choices analyze, memorize, and evaluate. Meanwhile, 10 students (45\%) had a fairly good reading ability and musical score mastery. Another student of 7 people (32\%), have the ability to read and control the music score is not good. This can be seen from the results of the questionnaire given, where the average answer is "studying the music score" in the before I begin reading score; answer "mark the music score with a pencil" in the While I reading music score; and answer "remember and evaluate the read music score".

\section{DISCUSSION}

In playing music, including playing guitar, students not only demand their skills, but also are required to have knowledge and insight related to the music works that will be played. Knowledge and skills need to be integrated with each other. Therefore, this is a very complex activity when playing music, and requires critical thinking skills, and metacognitive awareness.Playing music skill, as one of the basic skills of successful music instrumental performers, being based on extremely complex cognitive and musical mechanisms, is a very important indicator of the level of musical abilities and musical competencies, more valid and reliable than the final, expert performance that is presented at music examinations and and competitions. ${ }^{10}$

Of the twenty-two students who were participants in this study, it was found that only five students used metacognition thinking strategy well. Meanwhile, ten students less optimal in using the thinking strategy. Seven other students were weak in using their thinking strategies, so they were weak in knowledge metacognition. Metacognition is an essential part of any musician's repertoire of cognitive skills. A Musician must be able to recognize the requirements and identify the difficulties of musical task. Therefore, the students must apply appropriate strategies and monitor progress toward completion of the task, namely playing music in guitar class. ${ }^{5}$ Related to this, data from interviews revealed that students were weak in metacognitive behavior and metacognitive awareness, so that students cannot use their abilities and ways of thinking properly. This is because the lecturer cannot promote metacognition awareness by designing and implementing instructional strategies that encourage music students to engage in reflection, selfassessment, and thinking critically well.

Based on the results of research that has been obtained, it can be said that in playing music, especially in the guitar class, it is important to know what is known about the music that will be played. Therefore, music educators need to promote metacognitive awareness in students, so that students are able to develop their thinking strategies well in playing music, especially in guitar classes. This expression 
is reinforced by the results of previous studies that have been found ${ }^{11}$ namely metacognitive strategies had positive effects on the guitar education.

However, the research findings obtained revealed that only 5 students had the ability to read music scores in either category. This shows that not many students have the ability to read aspects of music scores well. In addition, there are still many students who do not use their thinking strategies as well. This is due to the fact that students lack understanding of how music should play well. This relates to the ability of students to present the work of music being played. The teacher can use the metacognitive teaching approach with four-steps models, consisting of a planning stage, playing stage, evaluation stage, and new strategies stage $\mathrm{e}^{12}$. The four stages are explained as follows.

The Planning stage included analyzing a piece prior to performing, identifying key features, finding patterns, and naming parts that may seem difficult. Students were continuously encouraged to provide examples and verbalize the strategies they might use to play sections of the piece. The process of analysis musical works is almost never done by some students in learning music, especially the practice of musical instruments. This is indicated by the results of research on quantitative data that 7 people $(32 \%)$, have the ability to read and control the music score is not good. This is what makes students do not know and understand the aspects of music contained in the music score. Meanwhile, analysis musical works by presenting these musical works has a close relationship. However, historically the two things have used different methods in their implementation. Analysis and performance are mutually supportive endeavors that broaden our musical understanding in different but related ways ${ }^{13}$. Based on this expression, it can be said that the importance of analyzing the music that will be played first. By analyzing the music, the students know and understand how to analyzing the music. Musical analysis and performance are mutually supportive endeavors that broaden our musical understanding in different but related ways. If it is associated with metacognition awareness, the second factor is still weak, namely knowledge metacognition.

Playing consisted of the student playing musical work while being encouraged to actively listen to the sound they were producing. This is rarely done by students in playing music. They tend to directly play the tones they see in musical scores, so that they can't think and understand how it should be done well. There are several advantages to listening to music if it is done seriously and with full concentration. These advantages include providing musical experience, and increasing high order thinking skills, and improving thinking strategies, because in listening to music students need to analyze, synthesize, and assess what they hear. This is reinforced by the results of research conducted by Johnson ${ }^{14}$ which studies Music Listening and Critical Thinking. In his research, it was revealed that critical thinking skills used to develop musical understanding include analysis, synthesis, comparing and differentiating, developing assessment criteria, making connections, recognizing patterns, and evaluating music information through active listening, reasoning, and reflection based on affective responses and previous musical experience. Therefore, teachers must provide opportunities for students to listen to musical works that will be played by students as often as possible. This is needed, so students are accustomed to listening to the work being played. Thus, students will get used to listening to the music they will play first, before the music work is played by themselves. If students are not given the experience of listening to music, especially those that will be played, then students will not have musical experiences, and this is related to the weakness of metacognition experiences, because metacognitive experiences are closely related to intuition, emotions, and experiences.

Meanwhile, the third stage of the metacognitive teaching approach is evaluation. The Evaluation stage consisted of the student identifying difficulties and successes, discussing the strategies she or he employed, and assessing whether they were successful in helping the student learn the song. Regarding evaluation, metacognition, which is also considered as the skill of evaluating one's own learning process and strategies, is considered to be effective on academic achievement, which is an assessment criterion of learning outputs. ${ }^{13}$ Mahdavi ${ }^{15}$ evaluated many studies on the subject as "the good news is that metacognitive skills are teachable and learnable as well to build up support for learners to better regulate their cognitive activities". Additionally, "metacognition is essential to successful learning because it enables individuals to better manage their cognitive skills and to determine weaknesses that can be corrected by constructing new cognitive skills". ${ }^{13} \mathrm{New}$ strategies were discussed by having students describe new ways they could approach/practice parts of the song if their strategies were not successful. The student then planned how these new strategies could be incorporated into their playing and subsequently replayed the song. The importance of metacognitive strategies in music education. ${ }^{16} \mathrm{~A}$ music learner can have a more effective music experience no matter their level is during and after the process, if they can set their own strategies, are aware of their strengths and weaknesses. Therefore, helping learners in developing their strategies required to make their own music is the responsibility of music educators. Developing own strategies is an approach, directly related to metacognitive processes. To be able to apply metacognition skills, the teacher needs to have a good knowledge of metacognition. This is reinforced by 
the findings submitted by Karaman et al. ${ }^{21}$ who state that: "Teachers, who have a central role in developing students' metacognitive behaviors, must have sufficient knowledge about metacognition, so that they can implement teaching strategies according to that.

\section{CONCLUSION}

Based on the results of research that has been obtained, it can be said that in playing music, especially in the guitar class, it is important to know what is known about the music that will be played. Therefore, lecturers need to promote metacognitive awareness in students, so that students are able to develop their thinking strategies well in playing music, especially in guitar classes.

\section{ACKNOWLEDGEMENT}

The authors would like to thank all reviewers and volunteers to make this study done. Authors also gratefully acknowledge Brain Science and Engineering Innovation Research Group, Mae Fah Luang University grant (2019) (MFU-grant no. 611U109005) and 2020, Thailand for the support.

\section{REFERENCES}

1 Ritchhart R. Intellectual Character: What it is, why it matters, and how to get it. In Machfauzia AN. Development of Intellectual Character in Musical Interpretation. Presented in the $10^{\text {th }}$ Anniversary Conference of the Asia-Pacific Network for Moral Education (APNME)4-7 December 2015, The University of Sidney, Australia.

2. Schraw G. Promoting General Metacognitive Awareness. In H.J. Hartman, Metacognition in Learning and Instruction. Texas: Springer Science, 2002.

3. Tobias $S$ and Everson HT. The Importance of Knowing What
You Know. In Hacker DJ, Dunlosky J, Graesser AC. Handbook of Metacognition in Education. New York: Routledge, Taylor \& Francis, 2009.

4. Louca EP. The Concept and Instruction of Metacognition. Journal of Teacher Development 2003; 7(1): 77-79.

5. Benton CW. Promoting Metacognition in Music Classes. Music Educators Journal 2013; 100(2): 52-59.

6. Hallam S. Music Psychology in Education. In Bogunović \& Vujović, Metacognitive Strategies in Learning Sight-Singing. Psihološkaistraživanja 2012; 15(2): 115-133.

7. Haynie M and Shepherd DA. A Measure of Adaptive Cognition for Enterpreneurship Research. Journal of Entrepreneurship Theory and Practice 2009; 15: 695-714.

8. Özkan A and Bülent A. Relation between Metacognitive Awareness and Participation to Class Discussion of University Students. Universal Journal of Educational Research. 2018; 6(1): 11-24. DOI: 10.13189/ujer. 2018.060102.

9. Leon J, Núñez JL, Alfonso ZR and Bordón B. Music Academic Performance: Effect of Intrinsic Motivation and Critical Thinking. Revista de Psicodidáctica. 2015; 20(2): 377-391.

10. Bogunović T and Vujović J. Metacognitive Strategies in Learning Sight-Singing. Psihološkaistraživanja 2012; 15(2): 115-133.

11. Yokuş T. Üstbilişin Gitar Performans Başarısına Etkisi. In Okay H, Evaluation of Metacognitive Competence Of Pre-Service Music Teachers In Terms Of Some Variables. Academic Journal. 2016; 11(8): 713-720.

12. Noa K. Metacognitive Instruction: How to Foster Smarter, More Independent Learners. Bullet Proof Musician [Online] 2016 [Cited 2019 December 4] Available from URL: https:// bulletproofmusician.com/metacognitive-instruction-how-tofoster-smarter-more-independent-learners/.

13. John L, Michael G. Analysis, Performance, and Images of Musical Sound: Surfaces, Cyclical Relationships, and the Musical Work. Journal of Current Musicology. 2007; 84: 53-78.

14. Johnson DC. Music Listening And Critical Thinking. International Journal of The Humanities. 2006; 2(2): 1163-1164.

15. Mahdavi M. An overview: Metacognition in education. In Okay H, Evaluation of Metacognitive Competence of Pre-Service Music Teachers in Terms of Some Variables. Academic Journal. 2016; 11(8): 713-720.

16. Leong $\mathrm{S}$. Metacognition and creativity in music assessment. In Okay $\mathrm{H}$, Evaluation of Metacognitive Competence of PreService Music Teachers in Terms of Some Variables. Academic Journal. 2016; 11(8): 713-720.

\footnotetext{
Authors Contribution:

ANM- Concept and design of the study, statistically analyzed and interpreted, manuscript preparation, critical revision of the manuscript; D- Concept and design of the study, manuscript preparation, critical revision of the manuscript, critical revision of the manuscript; PS- Manuscript preparation, Critical revision of the manuscript

Work attributed to:

Department of Music Education, Yogyakarta State University, Yogyakarta, Indonesia.

Graduate School of the Indonesia Institute of the Arts Yogyakarta, Yogyakarta, Indonesia.

Brain Science and Engineering Innovation Research Group, School of Anti-Aging and Regenerative Medicine, Mae Fah Luang University, Thailand.

Orcid ID:

Ayu Niza Machfauzia - (1) https://orcid.org/0000-0002-7490-3312

Dr. Djohan - (1) https://orcid.org/0000-0002-6705-3436

Dr. Phakkharawat Sittiprapaporn - (i) https://orcid.org/0000-0002-4103-9396

Source of Support: Brain Science and Engineering Innovation Research Group, Mae Fah Luang University grant (2019) (MFU-grant no. 611U109005) and 2020, Thailand, Conflict of Interest: None.
} 